\title{
Pattern of childhood brucellosis in Najran, south Saudi Arabia in 2013-2017
}

Ghadi Mohammed Al Hashan ${ }^{1}$, Nagah Mohamed Abo el-Fetoh ${ }^{2}$, Iman Ali Nasser ${ }^{3}$, Atheer Raja Alyami ${ }^{1}$, Albatool Saleh Hassan Almagbool ${ }^{4}$, Taghreed Ahmad Eidih Hatuwh ${ }^{4}$, Fatimah Hamad Saleh Alyami ${ }^{4}$, Maram Hamad Al Yami ${ }^{4}$, Manar Hamad Alqahtani ${ }^{4}$, Nouf Mubarak Ali Almardhamah ${ }^{4}$, Tahani Mohammed Alanazi ${ }^{4}$, Wafaa Mohamed Bakr Ali ${ }^{5}$, Ahad Mesfer Halzaa ${ }^{4}$, Ayah Abdullah Alshehri ${ }^{4}$

${ }^{1}$ Medical Intern, Najran University, Najran, Kingdom of Saudi Arabia

2 Associate Professor, Family and Community Medicine Department, Faculty of Medicine, Northern Border University, Arar, Kingdom of Saudi Arabia

${ }^{3}$ Assistant Professor, Pediatric Department, Faculty of Medicine, Najran University, Najran, Kingdom of Saudi Arabia

${ }^{4}$ Medical Student, Najran University, Najran, Kingdom of Saudi Arabia

${ }^{5}$ Pharmacy Student, Faculty of Pharmacy, Sohag University, Sohag, Egypt

Type of article: Original

\begin{abstract}
Background: With more than 500,000 new cases annually, human brucellosis is the commonest zoonotic disease worldwide. In some endemic countries, its prevalence is more than 10 per 100,000 population.

Objective: The aim of this study was to determine the magnitude of the problem and the clinical features, laboratory findings, treatment given and complications seen in children with brucellosis in Najran City, Kingdom of Saudi Arabia.

Methods: This is a case-series study by analysis of data of children known or diagnosed to have brucellosis for the last 4 years in Najran City. Data was obtained by reviewing the hospital records of the Maternity and Children Hospital and Najran Armed Forces Hospital in Najran during the period from 2013 to 2017. The statistical analysis was carried out using SPSS version 16.0. Since it was the first report of brucellosis on the study population, we used descriptive statistics (frequency, proportion, mean, and standard deviation) for presenting the findings.

Results: We studied 57 diagnosed cases of child brucellosis throughout the past 4 years in Najran, south Saudi Arabia with an average number of about 12 cases per year. Of the cases, $15.8 \%$ reported a history of ingestion of raw milk and dairy product and only $1.8 \%$ of them reported a history of animal contact while $82.4 \%$ confirmed unknown mode of transmission. Fever was the only finding in $36.8 \%$, fever and arthralgia $21.1 \%$, and fever and myalgia 19.3\%. Two thirds of the cases were diagnosed by standard agglutination test (SAT). Hepatosplenomegaly was found in $10.5 \%$. Rifampicin was the antibiotic of choice and $70.2 \%$ of cases have been cured but $3.5 \%$ relapsed and $1.8 \%$ died from complications.

Conclusions: Results suggest brucellosis be considered in every child living in an endemic area, showing symptoms of fever and having a history of ingestion of raw milk and dairy product and/or animal contact.

Prevention should rely on health education of the public about different issues of the disease including boiling raw milk.

Keywords: Brucellosis, Najran, Saudi Arabia
\end{abstract}

\section{Corresponding author:}

Ghadi Mohammed Al Hashan, Najran University, Najran, Kingdom of Saudi Arabia.

Tel: +966551193496, Email: ghadimhmd@hotmail.com

Received: October 01, 2017, Accepted: November 15, 2017, Published: December 2017

iThenticate screening: October 16, 2017, English editing: November 27, 2017, Quality control: December 02, 2017

This article has been reviewed / commented by three experts

(C) 2017 The Authors. This is an open access article under the terms of the Creative Commons Attribution-NonCommercialNoDerivs License, which permits use and distribution in any medium, provided the original work is properly cited, the use is non-commercial and no modifications or adaptations are made. 


\section{Introduction}

Brucellosis is a zoonosis caused by the Gram-negative bacteria, Brucella spp. The disease spreads to humans through raw dairy products, infected meat from domestic livestock (sheep, goats, cattle, water buffalo, camels and pigs) and contact with their secretions and carcasses. With more than 500,000 new cases annually, human brucellosis is the commonest zoonotic disease worldwide. In some endemic countries, its prevalence is more than 10 per 100,000 population. It is hyperendemic in areas such as the Mediterranean Basin, Arabian Peninsula, India, Mexico, and Central and South America although it is generally seen throughout the world (1). The most common presenting signs of Brucella infection are fever and arthritis. Poly-arthritis is less common than mono-arthritis. This can be a cause of confusion with pyogenic arthritis in children; therefore, in an area of people where brucellosis is prevalent, alertness to the disease should prompt the investigation of it, and physicians should also be alert for Brucella arthritis (2). The gold standard for prevention of brucellosis infection is to avoid undercooked meat, unpasteurized dairy products, including milk, cheese and ice cream, and using rubber gloves, goggles, gowns, and aprons for people who deal with animals (3). The first report in literature of human brucellosis in Saudi Arabia was nearly 2 decades ago. Kambal et al. (4) explained the clinical features and laboratory diagnosis of the disease from the Riyadh area in detail. The clinical features of 140 patients with brucellosis in Saudi Arabia was reviewed by Madkour et al. (5). Of these patients, 90 had low back pain and/or arthritis at presentation; 32 had subacute hepatitis, abortion occurred in 6, Epididymo-orchitis in 6, and 2 had endocarditis. The study reported that brucellosis may be misdiagnosed because it is usually accompanied with other illnesses. An investigation into the epidemiology of brucellosis was carried out by Al-Zeftawy et al. (6) among abattoir workers from slaughterhouse sites in Mecca Medina Dammam, Riyadh, Jeddah, Qassim, and Al-Hasa. The incidence of brucellosis among the workers was at $1.8 \%$. Positive titers were from veterinarians, butchers, and laborers (all clinically symptomless) while negative titers were in administrative personnel, maintenance workers and drivers. The fact that brucellosis is endemic in the Kingdom became clearer in the early 1980s. Several reasons have been considered but the most prominent of them is the increase in the importation of animals from areas where brucellosis is endemic, especially some African countries. Consumption of raw milk and to a lesser extent contact with infected animals or their products are the main routes of infection. The consumption of fresh, unpasteurized milk from camels is a traditional practice, and people believe that boiling removes the goodness from the milk. To our knowledge, no similar research had been carried out in Najran city, in the southern area in the Kingdom of Saudi Arabia, so we decided to conduct this study. The general objective of this research was to determine the magnitude of the problem of brucellosis among children attending the Maternity and Children Hospital and Najran Armed Forces Hospital in Najran throughout the past 4 years, from 2013 to 2017 . The specific objectives were: 1) to show the mode of transmission, clinical features and laboratory findings, 2) to show the treatment given to the cases, and 3) to show the complications seen in children with brucellosis in Najran City, Kingdom of Saudi Arabia.

\section{Material and Methods}

This is a case-series study by analysis of data of children known or diagnosed to have brucellosis for the last 4 years in Najran City. They were selected from the Maternity and Children Hospital and Najran Armed Forces Hospital in Najran. The record charts of all children who presented from 2013 to 2017, with a clinical diagnosis of brucellosis based on manifestations and laboratory findings, were reviewed. Information on age, gender, history of raw milk or milk products ingestion, presenting symptoms and physical signs were extracted from the patients' records. We also noted the results of routine laboratory tests, treatment given, outcome of treatment and complications. Data were analyzed by SPSS version 16.0 (SPSS Inc., Chicago, Illinois, USA). Sample characteristics were summarized as numbers and percentages for categorical variables. Statistical methods (frequency, proportion, mean, and standard deviation) will be used in the evaluation of the research data. Before starting data collection ethical approval was obtained from the Research Ethics Committee of the Faculty of Medicine, Najran University. During data collection stage, informed consent was secured from each participant. The questionnaires used in data collection were anonymous and confidentiality of data was assured.

\section{Results}

According to the study, $15.8 \%$ of the cases were aged between $2-4$ years, 28.1 between $4-8$ years old, $21.1 \%$ aged between 8-10 years and 26.3\% more than 10 years old. Table 1 illustrates age group, sex, mode of transmission, presenting symptoms and duration of symptoms of the studied brucellosis cases. Regarding sex; about two thirds of studied cases were males and one third were females. The majority (82.4\%) of cases confirmed unknown mode of transmission while 15.8 reported history of ingestion of raw milk and dairy product and only $1.8 \%$ of them reported history of animal contact. As regards presenting symptoms; more than one third (36.8\%) of cases presented with fever and arthralgia, $21.1 \%$ fever and myalgia, 19.3\% fever and bone pain, $14.1 \%$ fever, vomiting and diarrhea, 
$5.4 \%$ fever, sweating and skin rash and only 3.5\% with fever and respiratory symptoms. Most (86\%) cases had acute symptoms (0-2 months), only $10.5 \%$ had sub-acute symptoms (2-12 months) and just 3.5\% had chronic symptoms $(<12$ months). About one third of the cases were diagnosed by Standard agglutination test (SAT) + Blood culture, another third were diagnosed by Standard agglutination test (SAT) only, $12.3 \%$ by blood culture only, $10.5 \%$ clinically + Standard agglutination test (SAT) and 7\% clinically + Blood culture. Regarding ultrasound examination; only $10.5 \%$ found hepatosplenomegaly and $1.8 \%$ found endocarditis. In addition, about one fifth of cases had positive X-ray and 3.5\% positive for MRI. Table 2 illustrates type and duration of treatment and completeness of the medication course of the studied brucellosis cases. More than two thirds $(64.9 \%)$ of the cases were treated with a combination of Rifampicin with other antibiotics and the remaining $29.8 \%$ treated with Rifampicin only and $5.3 \%$ with other antibiotics. Most $(56 \%)$ of the cases had treatment for $1-2$ months, $10.5 \%$ two weeks, $10.5 \%$ had treatment for one week and $21.1 \%$ for 3 weeks. About $82.5 \%$ of the cases had a complete course of treatment. Table 3 illustrates laboratory findings of the studied brucellosis cases. A total of $17.5 \%$ of the cases had Low $\mathrm{Hb}$ level. Leucocyte count was high in only $5.3 \%$ of the cases and low in $7 \%$. Platelet count was high in $14 \%$ and low in $1.8 \%$. ESR was high in one third of the cases and low in 5.3\% of them. CRP was high in 17.5\% and low in 5.3\%. Finally, regarding the outcome of treatment of the studied brucellosis cases, 40 patients $(70.2 \%)$ had recovery, while relapse and death from complications of the disease were seen in $3.5 \%$ and $1.8 \%$ of the patients respectively. The outcome was unknown for $24.6 \%$ of the patients.

Table 1. Age group (in years), sex, mode of transmission, presenting symptoms and duration of symptoms of the studied Brucellosis cases, Najran, Kingdom of Saudi Arabia, 2014-2017

\begin{tabular}{|c|c|c|c|}
\hline \multicolumn{2}{|l|}{ Variable } & $\mathrm{n}$ & $\%$ \\
\hline \multirow[t]{6}{*}{ Age group (years) } & $0-1$ & 5 & 8.8 \\
\hline & $2-$ & 9 & 15.8 \\
\hline & $4-$ & 16 & 28.1 \\
\hline & $8-$ & 12 & 21.1 \\
\hline & $10+$ & 15 & 26.3 \\
\hline & Mean age $( \pm \mathrm{SD})$ & \multicolumn{2}{|c|}{$6.1 \pm 2.2$} \\
\hline \multirow[t]{2}{*}{ Sex } & Female & 20 & 35.1 \\
\hline & Male & 37 & 64.9 \\
\hline \multirow[t]{3}{*}{ Mode of transmission } & Unknown & 47 & 82.4 \\
\hline & History of animal contact & 1 & 1.8 \\
\hline & History of ingestion of raw milk and dairy product. & 9 & 15.8 \\
\hline \multirow[t]{6}{*}{ Presenting symptoms } & Fever, Arthralgia & 21 & 36.8 \\
\hline & Fever, Myalgia & 12 & 21.1 \\
\hline & Fever, Bone pain & 11 & 19.3 \\
\hline & Fever, Vomiting, Diarrhea & 8 & 14.1 \\
\hline & Fever, Sweating and Skin rash & 3 & 5.4 \\
\hline & Fever and Respiratory symptoms & 2 & 3.5 \\
\hline \multirow[t]{3}{*}{ Duration of symptoms (months) } & $0-2$ (acute) & 49 & 86.0 \\
\hline & 2-12 (sub-acute ) & 6 & 10.5 \\
\hline & $>12($ chronic $)$ & 2 & 3.5 \\
\hline \multirow[t]{7}{*}{ Methods of diagnosis } & Blood culture & 7 & 12.3 \\
\hline & Clinically + Blood culture & 4 & 7.0 \\
\hline & Clinically + Standard agglutination test (SAT) & 6 & 10.5 \\
\hline & Clinically + Standard agglutination test (SAT), Blood culture & 3 & 5.3 \\
\hline & Standard agglutination test (SAT) & 17 & 29.8 \\
\hline & Standard agglutination test $(\mathrm{SAT})+$ Blood culture & 17 & 29.9 \\
\hline & Others & 3 & 5.3 \\
\hline \multirow[t]{3}{*}{ Results of ultrasound examination } & No finding & 50 & 87.7 \\
\hline & Hepatomegaly, Splenomegaly & 6 & 10.5 \\
\hline & Endocarditis & 1 & 1.8 \\
\hline X-RAY & Yes & 12 & 21.1 \\
\hline MRI & Yes & 2 & 3.5 \\
\hline
\end{tabular}


Table 2. Type and duration of treatment and completeness of the medication course of the studied Brucellosis cases, Najran, Kingdom of Saudi Arabia, 2014-2017

\begin{tabular}{|l|l|l|l|}
\hline Variable & $\mathrm{n}$ & $\%$ \\
\hline Type of treatment & Rifampicin only & 17 & 29.8 \\
\cline { 2 - 5 } & Rifampicin and other antibiotics & 37 & 64.9 \\
\cline { 2 - 5 } & Other antibiotics (Amoxicillin, azithromycin and bacterium) & 3 & 5.3 \\
\hline \multirow{3}{*}{ Duration of treatment (weeks) } & 1 week & 6 & 10.5 \\
\cline { 2 - 5 } & 2 weeks & 6 & 10.5 \\
\cline { 2 - 5 } & 3 weeks & 12 & 21.1 \\
\cline { 2 - 5 } & $1-2$ months & 33 & 56.0 \\
\hline Completeness of the medication course & Yes & 10 & 82.5 \\
\cline { 2 - 4 } & No & 17.6 \\
\hline
\end{tabular}

Table 3. Laboratory findings of the studied Brucellosis cases, Najran, Kingdom of Saudi Arabia, 2014-2017

\begin{tabular}{|l|l|l|l|}
\hline \multicolumn{2}{|l|}{ Laboratory finding } & $\mathrm{n}$ & $\%$ \\
\hline Low Hb level & & 10 & 17.5 \\
\hline Leucocyte count & High & 3 & 5.3 \\
\cline { 2 - 4 } & Low & 4 & 7.0 \\
\hline \multirow{2}{*}{ Platelet count } & High & 8 & 14.0 \\
\cline { 2 - 4 } & Low & 1 & 1.8 \\
\hline \multirow{2}{*}{ Erythrocyte sedimentation rate (ESR) } & High & 17 & 29.8 \\
\cline { 2 - 3 } & Low & 3 & 5.3 \\
\hline \multirow{2}{*}{ C reactive protein (CRP) } & High & 10 & 17.5 \\
\cline { 2 - 3 } & Low & 3 & 5.3 \\
\hline
\end{tabular}

\section{Discussion}

Brucellosis is the most common zoonotic infectious disease worldwide, and affects more than 500, 000 people each year (7). This study was conducted to determine the main clinical presentation in children with brucellosis in Najran City, Kingdom of Saudi Arabia through determination of demographic profile of children with brucellosis in terms of gender, age and to describe the clinical manifestation of children diagnosed with brucellosis in the past 4 years from 2013 to 2017 . In this study; $64.9 \%$ of studied cases were males and $35.1 \%$ were females. The mean ( \pm SD) of cases was about $6.1 \pm 2.2$ years old. Our results were not in line with a Turkish study (8) which reported mean age of the study population $8.4 \pm 6.4$ years, $53.2 \%$ females and $46.8 \%$ males. Our study found that 15.8 reported a history of ingestion of raw milk and dairy product and only $1.8 \%$ of them reported a history of animal contact, which was less than the El-Koumi MA et al. study in Saudi Arabia (9) which found (83\%) of the cases ingested raw animal milk and $(45 \%)$ had a positive family history of brucellosis. This agreed with findings of Briones Lara et al. (10) which reported $61 \%$ of cases had consumed potentially infected milk or dairy products. This was in line with a Buzgan T et al. study (1) which reported that (63.6\%) had a history of raw milk and dairy products. A study by Al-Eissa determined that brucellosis presents in both genders and all ages of the Saudi population, and that the most common form of acquiring brucellosis is through the ingestion of untreated milk or milk products obtained mainly from infected livestock, a traditional practice upheld by nomadic customs and the dietary habits of the people (12). The common presenting symptoms and signs included: $36.8 \%$ fever and arthralgia, $21.1 \%$ fever and myalgia, $19.3 \%$ fever and bone pain, $14.1 \%$ fever, vomiting and diarrhea, 5.4\% fever, sweating and skin rash and only $3.5 \%$ with fever and respiratory symptoms. An El-Koumi MA et al. study (9) reported excessive sweating (68\%), bone aches (62\%), chills (55\%), arthritis (32\%), hepatomegaly (18\%) and splenomegaly (15\%) as presenting symptoms. Correspondingly, incidence of leucopenia in $38 \%$, anemia in $64 \%$, and thrombocytopenia in $28 \%$ of brucellosis candidates in south-western Saudi Arabia was reported by Dr. Benjamin Annobil (13). The study of Al Shaalan M et al. (6) showed that arthritis was prevalent in $70 \%$ of patients, $20 \%$ of patients presented with a non-specific febrile illness without localizing signs, and $10 \%$ had a febrile illness with uncommon presentations. The study by Andriopoulos $\mathrm{P}$ et al. (14) reported clinical manifestations including non-specific symptoms (malaise, fever, headache, sweats, arthralgia, and lower back pain) and findings such as splenomegaly (51\%), osteoarticular involvement $(42 \%)$, cervical lymphadenitis $(31 \%)$, hepatomegaly $(25 \%)$, genitourinary involvement (13\% of men), cholecystitis $(2 \%)$, breast abscess $(0.7 \%)$, and acute abdomen $(0.7 \%)$. A study by Buzgan $\mathrm{T}$ et al. (1) discovered that the most commonly seen symptoms were arthralgia (73.7\%) and fever $(72.2 \%)$, while the most frequent clinical findings were fever $(28.8 \%)$ and hepatomegaly $(20.6 \%)$. About one third of the cases were diagnosed by Standard 
agglutination test (SAT) + Blood culture, another third were diagnosed by Standard agglutination test (SAT) only, $12.3 \%$ by blood culture only, $10.5 \%$ clinically + Standard agglutination test (SAT) and 7\% clinically + Blood culture. The Mantur B et al. study (16) reported that in (16.1\%) cases brucellosis was suspected clinically, whereas in $(83.87 \%)$ cases, only serological evidence of brucellosis confirmed the diagnosis. Regarding treatment outcome; $3.5 \%$ of cases relapsed and $1.8 \%$ died from complications. This was less than the findings of a Bosilkovski M study (15) which reported relapses were $(6.6 \%)$, and therapeutic failures in $(0.9 \%)$ of the children. A Buzgan T et al. study (1) reported overall relapse rate for patients with brucellosis $(4.7 \%)$, the highest relapse rate, $(8.5 \%)$, was observed in the group of patients with osteoarticular involvement. Fathallah M et al. (16) recorded relapse in 18 patients $(11.3 \%)$, pneumonia and epididymo-orchitis $(1.3 \%)$. Regarding drugs for treatment; more than two thirds of the cases were treated by Rifampicin with other antibiotics and the remaining third were treated with Rifampicin only. Fathallah $\mathrm{M}$ et al. (16) in northern Saudi Arabia used Rifampicin and doxycycline in (54.7\%), doxycycline and streptomycin in (20.8\%), and rifampicin and streptomycin in (12.6\%). Regarding the study limitation, we should say that the prevalence of the disease among the population at risk of getting the disease (veterinarians, butchers, and Lab. personnel) in Najran city, south Saudi Arabia was not discussed because it was a hospital based study. But fortunately, all the needed data was obtained from the well-organized records of the hospital.

\section{Conclusions}

There were 57 diagnosed cases of child brucellosis throughout the past 4 years in Najran, south Saudi Arabia with an average number of about 12 cases per year. Therefore, brucellosis should be considered in every child from an endemic area presenting with a febrile illness and a history of ingestion of raw milk and dairy product and/or animal contact.

\section{Acknowledgments:}

As the paper was original, the authors would like to thank the staff members of the Maternity and Children Hospital and Najran Armed Forces Hospital in Najran in addition to the record keepers, who helped us in different steps of data collection and preparation of the manuscript. Authors also acknowledge the personnel who conducted the data entry and statistical analysis of the research data.

\section{Conflict of Interest:}

There is no conflict of interest to be declared.

\section{Authors' contributions:}

All authors contributed to this project and article equally. All authors read and approved the final manuscript.

\section{References:}

1) Buzgan T, Karahocagil MK, Irmak H, Baran AI, Karsen H, Evirgen O, et al. Clinical manifestations and complications in 1028 cases of brucellosis: a retrospective evaluation and review of the literature. Int $\mathrm{J}$ Infect Dis. 2010; 14(6): e469-78. doi: 10.1016/j.ijid.2009.06.031. PMID: 19910232.

2) Pappas G, Akritidis N, Bosilkovski M, Tsianos E. Brucellosis. N Engl J Med. 2005; 352: 2325-36. doi: 10.1056/NEJMra050570.

3) Kambal AM, Maghoub ES, Jamjoon GA, Chawdhury MNH. Brucellosis in Riyadh, Saudi Arabia: amicrobiological and clinical study. Trans R Soc Trop Med Hyg. 1983; 77(6): 820-4. doi: 10.1016/00359203(83)90297-3. PMID: 6665836.

4) Madkour MM, Rahman A, Mohamed E, Talukder MA, Kudwah AJN. Brucellosis in Saudi Arabia. Saudi Med J. 1985; 6: 324-32. doi: 10.5144/0256-4947.1999.403.

5) Al-Zeftawi NM, Al-Issa M, Bekairi SI, Radwan AI, Hafez SM. Epidemiology of Brucellosis among abattoir workers in Saudi Arabia. Ann Saudi Med. 1986; 6: S29-31. doi: 10.1177/146642409311300503.

6) Shaalan MA, Memish ZA, Mahmoud SA, Alomari A, Khan MY, Almuneef M, et al. Brucellosis in children: clinical observations in 115 cases. Int J lnfec Dis. 2002; 6(3): 182-6. PMID: 12718832.

7) Pappas G, Papadimitriou P, Akritidis N, Christou L, Tsianos EV. The new globalmap of human brucellosis. Lancet Infect Dis. 2006; 6(2): 91-9. doi: 10.1016/S1473-3099(06)70382-6. PMID: 16439329.

8) Gül S, Satilmiş ÖK, Ozturk B, Gökçe Mİ, Kuscu F. Seroprevalence of Brucellosis among Children in the Middle Anatolia Region of Turkey. J Health Popul Nutr. 2014; 32(4): 577-9. PMID: 25895189, PMCID: PMC4438686. 
9) El-Koumi MA, Afify M, Al-Zahrani SH. A Prospective Study of Brucellosis in Children: Relative Frequency of Pancytopenia. Mediterr J Hematol Infect Dis. 2013; 5(1): e2013011. doi: 10.4084/MJHID.2013.011. PMID: 23505599, PMCID: PMC3591276.

10) Briones-Lara E, Palacios-Saucedo Gdel C, Martínez-Vázquez IO, Morales-Loredo A, Bilbao-Chávez Ldel P. [Response to the treatment of brucellosis among children. Evaluation with Huddleson reaction and PCR]. Rev Med Inst Mex Seguro Soc. 2007; 45(6): 615-22. PMID: 18593545.

11) Al-Eissa YA. Brucellosis in Saudi Arabia: Past, present and future. Ann Saudi Med. 1999; 19(5): 403-5. doi: 10.5144/0256-4947.1999.403. PMID: 17277503.

12) Benjamin B, Annobil SH. Childhood brucellosis in southwestern Saudi Arabia: a 5-year experience. J Trop Pediatr. 1992; 38(4): 167-72. doi: 10.1093/tropej/38.4.167. PMID: 1527811.

13) Bosilkovski M, Krteva L, Caparoska S, Labacevski N, Petrovski M. Childhood brucellosis: Review of 317 cases. Asian Pac J Trop Med. 2015; 8(12): 1027-32. doi: 10.1016/j.apjtm.2015.11.009. PMID: 26706674.

14) Andriopoulos P, Tsironi M, Deftereos S, Aessopos A, Assimakopoulos G. Acute brucellosis: presentation, diagnosis, and treatment of 144 cases. Int J Infect Dis. 2007; 11(1): 52-7. doi: 10.1016/j.ijid.2005.10.011. PMID: 16651018.

15) Mantur BG, Akki AS, Mangalgi SS, Patil SV, Gobbur RH, Peerapur BV. Childhood brucellosis--a microbiological, epidemiological and clinical study. J Trop Pediatr. 2004; 50(3): 153-7. doi: 10.4103/02550857.34758. PMID: 15233191.

16) Fallatah SM, Oduloju AJ, Al-Dusari SN, Fakunle YM. Human brucellosis in Northern Saudi Arabia. Saudi Med J. 2005; 26(10): 1562-6. PMID: 16228056. 